CLINICAL STUDY

\title{
Effects of resistance versus endurance training on serum adiponectin and insulin resistance index
}

\author{
Sajad Ahmadizad ${ }^{1}$, Amir Hossein Haghighi and Mohammad Reza Hamedinia \\ Department of Sports Sciences, Tarbiat Moallem University, Sabzavar, Iran and ${ }^{1}$ Department of Sports and Exercise Physiology, Faculty of Sports and \\ Exercise Sciences, Shahid Beheshti University, Tehran, 198396 3113, Iran
}

(Correspondence should be addressed to S Ahmadizad; Email: sahmadizad@yahoo.com)

\begin{abstract}
Purpose: The purpose of the present study was to investigate the effects of resistance and endurance training on serum adiponectin and insulin resistance index $\left(\mathrm{S}_{\mathrm{I}}\right)$ in healthy men.

Methods: Twenty-four healthy males (age, 35-48 years) participated in the study. The subjects were randomly assigned to one of three groups: endurance training group $(n=8)$, resistance training group $(n=8)$ and control group $(n=8)$. Blood samples were taken in fasting state from all subjects. The experimental groups performed either endurance or resistance training 3 days a week for 12 weeks. The endurance training programme included continuous running at an intensity corresponding to $75-85 \%$ of maximal heart rate, while resistance training consisted of four sets of circuit weight training for 11 stations and at an intensity corresponding to $50-60 \%$ of one-repetition maximum. The maximum numbers of repetitions in each station was 12 .

Results: There were significant negative correlations between serum adiponectin and body fat percentage, waist-to-hip ratio, body mass index and the insulin resistance index at baseline, whereas changes in response to training were not significantly correlated. Both endurance and resistance training resulted in a significant decrease in the $S_{I}$ in comparison with the control group. However, serum adiponectin did not change significantly in response to resistance and endurance training. Conclusion: Endurance and resistance training caused an improvement in insulin resistance in healthy men, but this improvement was not accompanied by increased adiponectin levels.
\end{abstract}

European Journal of Endocrinology 157 625-631

\section{Introduction}

Adipose tissue secretes multiple proteins known as adipocytokines that modulate various biological functions. One of these adipocytokines is adiponectin (1), which is reduced with obesity, increased insulin resistance, dyslipidaemia and diabetes. Adiponectin may be a marker for coronary artery disease (2) and seems to have protective metabolic and anti-inflammatory properties (3), which prevents atherosclerosis (4).

Physical inactivity is one of the main cardiovascular risk factors (5). Improvement in cardiovascular function by physical activity has been attributed to exerciseinduced positive changes in metabolic abnormalities and risk factors that are associated with atherosclerosis $(5,6)$. Adiponectin and insulin sensitivity play an important role in the development of atherosclerosis (4). Body weight reduction as a result of endurance training increases circulating levels of adiponectin, and the increase in adiponectinaemia is associated with decrease in body mass index (BMI) and the improvement in insulin sensitivity (7). As another therapy to increase insulin sensitivity along with weight reduction, exercise training might also affect adipocyte metabolism and result in changes in adiponectinaemia.

It has been established that endurance training increases insulin sensitivity and causes improvements in insulin sensitivity. However, there is still controversy with regard to the effects of endurance training on adiponectin. For example, different authors have demonstrated no change (3, 8-11), an increase (12-14) or a decrease (15) in adiponectin following different training protocols.

In recent years, resistance training or weight training has become a very popular form of exercise to improve physical fitness, enhance performance, prevent injuries and increase muscle size $(16,17)$. The physiological and biochemical responses to resistance exercise are different from those exhibited in response to endurance exercise (18). There are few studies that have examined the effects of resistance training on adiponectin and insulin sensitivity (19-21) and the results are controversial. For example, recently Klimcakova et al. (20) have reported no changes in adiponectin concentration in response to 3 months of resistance training, while Fatouros et al. (19) investigated the effects of 6 months of resistance training with different intensities 
and reported significant increases in adiponectin after moderate- and high-intensity training but not after lowintensity training. In addition, Brooks et al. (21) demonstrated rises in adiponectin concentration after 14 weeks of high-intensity resistance training.

Different forms of resistance exercise induce different physiological adaptations. Circuit weight training is a form of resistance exercise that causes improvement in cardiovascular fitness (22). No previous study has investigated the effects of these types of training on insulin sensitivity and adiponectin concentration, and no previous studies have attempted to compare the responses of adiponectin and insulin sensitivity to both resistance and endurance exercise in middle-aged healthy men. Therefore, the present study was designed 1) to determine and compare the effects of circuit weight training and endurance training on insulin sensitivity and adiponectin concentration and 2) to explore the relationship between adiponectin and body composition changes in response to these two training protocols.

\section{Materials and methods}

\section{Subjects}

Twenty-four sedentary obese men who had no regular exercise for at least 12 months were recruited into this study. Subjects were randomly assigned to one of the three groups: endurance training group $(41.3 \pm 5.1$ years; $n=8)$, resistance training group $(40.9 \pm 3.2$ years; $n=8)$ or control group (38.6 \pm 3.2 years; $n=8)$. All subjects were asked to complete a personal health and medical history questionnaire, which served as a screening tool. All subjects were non-smokers and had no history of any kind of medical condition that would prevent them from participating in the exercise intervention. The University's ethics committee approved the experimental procedures and study protocols, which were fully explained to all subjects. A written consent form was signed by each subject after having read and understood the details of the experiments.

\section{Experimental design}

Following familiarisation, subjects were asked to report to the laboratory for an additional test session designed to determine one-repetition maximum (1-RM) for 11 exercises involving the upper and lower body. Maximal strength was determined using a concentric, 1-RM (23), as previously described (24). The warm-up consisted of riding a stationary bicycle for $5 \mathrm{~min}$, two sets of progressive resistance exercises similar to the actual exercises utilised in the main experiment, and 2-3 min of rest accompanied by some light stretching exercises. After the warm-up, subjects performed the 1-RM test, and the heaviest weight that could be lifted once using the correct technique was considered as 1-RM for all the exercises and used to calculate the percentage of resistance.

\section{Endurance training}

The endurance-training programme consisted of running at $75-85 \%$ of maximal heart rate $\left(\mathrm{HR}_{\max }\right)$ for 20-30 min per day, 3 days per week, for 12 weeks. The programme started with $20 \mathrm{~min}$ running for the first few sessions, and this was then changed to $30 \mathrm{~min}$ per session until the end of training. Each training session was started with a warm-up and finished with a cooldown. The exercise intensity was controlled by the authors, using a heart rate monitor, who ensured that it was between 75 and $85 \%$ of $\mathrm{HR}_{\max }$ throughout the trial. The training sessions were performed in University and were supervised by the researcher.

\section{Resistance training}

Two familiarisation sessions were designed to habituate subjects with the testing procedures and laboratory environment. The main aim of these sessions was to familiarise subjects with different resistance exercises using weight-training machines and also to familiarise them with performing the 1-RM test. During the familiarisation sessions, it was ensured that all subjects used the correct techniques for all exercises prior to taking part in the main test sessions. Resistance training consisted of 50-60 min of circuit weight training per day, 3 days a week, for 12 weeks. This training was circularly performed in 11 stations and included four sets with 12 maximal repetitions at $50-60 \%$ of $1-\mathrm{RM}$ in each station. Each exercise and set was separated by 30 s rest. General and specific warm-up were performed prior to each training session, as explained for the 1-RM determination, and each training session was followed by cool-down.

\section{Blood sampling and analysis}

Blood samples were obtained from all subjects at $0800 \mathrm{~h}$ after an overnight fast before and after the training programmes. Post-training blood samples from subjects in the training groups were obtained 4 days after their last exercise session. On the days before the blood samples were taken, subjects were asked to consume a weight-maintenance diet for 3 days and to avoid strenuous exercise for 4 days.

Serum glucose concentration was measured using the glucose oxidase method (glucose B-test, Wako pure chemical, Osaka, Japan). Serum insulin level was determined using ELISA technique using a microplate reader. Fasting sera kept at $-80{ }^{\circ} \mathrm{C}$ were used to measure serum adiponectin concentrations by RIA (Linco Research, St Charles, MO, USA). The intra- and inter-assay coefficients of variation for adiponectin were 
$<5 \%$. Before and after intervention, insulin resistance in fasting state was determined using a homeostasis model assessment (HOMA-IR) and was calculated from fasting insulin $\left(I_{\mathrm{F}}\right)$ and fasting glucose $\left(G_{\mathrm{F}}\right)$ as follows: HOMA-IR $=\left(I_{\mathrm{F}} \times G_{\mathrm{F}}\right) / 22.5(25)$. The units for $I_{\mathrm{F}}$ and $G_{\mathrm{F}}$ were $\mu \mathrm{U} / \mathrm{ml}$ and $\mathrm{mmol} / \mathrm{l}$ respectively. The validity and reliability of HOMA-IR have been ascertained in previous studies that have demonstrated a high correlation between HOMA-IR and the glucose clamp technique not only before, but also after, treatment in type 2 diabetic patients $(26,27)$.

\section{Anthropometric measurements}

BMI was calculated as weight (kilograms) divided by height (metres) squared. The subject's waist was measured midway between the lowest rib and the illiac crest. The hip circumference was measured at the widest part of the gluteal region. The waist-to-hip ratio (WHR) was then calculated. Body fat mass was determined by bioelectrical impedance analysis using a Body Composition Analyzer (Biospase, South Korea).

\section{Statistical analysis}

Descriptive statistics were computed and distributions of all variables were assessed for normality. Main effects of training modality (resistance and endurance) and time (before and after 12 weeks) and interaction between training modality and time were assessed using two-way analysis of variance (ANOVA). When ANOVA indicated the presence of a significant difference, post hoc comparisons using Bonferroni's method were applied to identify which mean differences were statistically significant. The relationships between variables at baseline and in response to training were determined using Pearson's and Spearman's correlation tests. Values are presented as mean ( \pm s.D.) unless otherwise stated. The level of significance in all statistical analyses was set at $P<0.05$.

\section{Results}

Physiological characteristics of the subjects at baseline and after 12 weeks of training are presented in Table 1 . Before the intervention, there were no significant differences in age, BMI, body weight, percentage of body fat, maximal $\mathrm{O}_{2}$ consumption $\left(\mathrm{VO}_{2}\right.$ max $)$ and WHR among the three groups. Baseline glucose metabolic profiles, including insulin sensitivity assessed by HOMAIR and serum adiponectin, were also similar in the three groups.

Maximal oxygen consumption increased significantly by $7 \pm 3.5$ and $5 \pm 4.1 \mathrm{ml} / \mathrm{kg}$ per min after endurance and resistance training respectively, while no significant change in the control group was found. Endurance and resistance training did not cause any significant changes in body weight, WHR and BMI when pre- and post-training values were compared (Table 1). However, both endurance and resistance training decreased the body fat percentage significantly (Table 1). Glucose concentrations before and after endurance training were $5.21 \pm 0.77$ and $5.16 \pm 1.0 \mathrm{mmol} / \mathrm{l}$ respectively, and those for resistance training were $5.09 \pm 0.65$ and $5.09 \pm 0.64 \mathrm{mmol} / \mathrm{l}$ respectively. Fasting serum glucose did not change significantly $(P>0.05)$ in response to endurance and resistance training. Insulin concentration declined significantly $(P<0.05)$ from $8.54 \pm$ 4.75 to $5.73 \pm 3.24 \mu \mathrm{U} / \mathrm{ml}$ and from $10.55 \pm 3.57$ to $6.41 \pm 3.07 \mu \mathrm{U} / \mathrm{ml}$, in response to endurance and resistance training respectively, while the changes in the control group after 12 weeks were not statistically significant.

Insulin resistance index, assessed by HOMA-IR was reduced significantly by 35.7 and $38.5 \%$ following 12 weeks of endurance and resistance training respectively, with no significant changes in the control group. When changes in HOMA-IR for the three groups were compared, statistical analysis revealed a significant $(P<0.05)$ difference between both experimental groups and control group (Fig. 1). However, changes in HOMA-IR were not significantly different between two training groups. Serum adiponectin concentration at baseline was negatively correlated with BMI $(R=-0.74, P<0.001)$, body fat percentage $(R=-0.64, P<0.001)$, WHR $(R=-0.59, P<0.002)$ and calculated insulin resistance $(R=-0.41, P<0.016)$. However, when changes in response to training were analysed statistically, there were no significant correlations among these variables. Statistical analysis did not show any significant effects of either endurance or resistance training on serum adiponectin concentration (Fig. 2). In addition, there were no significant differences among the adiponectin responses in the three groups.

Table 1 Physiological characteristics (mean \pm s.D.) of the subjects before and after 12 weeks of endurance training, resistance training and control condition.

\begin{tabular}{|c|c|c|c|c|c|c|}
\hline \multirow[b]{2}{*}{ Weight (kg) } & \multicolumn{2}{|c|}{ Endurance training } & \multicolumn{2}{|c|}{ Resistance training } & \multicolumn{2}{|c|}{ Control } \\
\hline & $83.1 \pm 6.8$ & $83.8 \pm 7.3$ & $82.3 \pm 10.0$ & $81.6 \pm 10.5$ & $83.6 \pm 11.0$ & $84.8 \pm 9.0$ \\
\hline Body fat (\%) & $22.8+1.9$ & $19.5+3.0^{\mathrm{a}}$ & $22.8+1.4$ & $18.3+4.1^{\mathrm{a}}$ & $25.6+4.6$ & $26.5+3.6$ \\
\hline BMI $\left(\mathrm{kg} / \mathrm{m}^{2}\right)$ & $27.9 \pm 2.2$ & $27.8 \pm 2.1$ & $28.3 \pm 2.3$ & $28.1 \pm 2.5$ & $29.4 \pm 4.6$ & $29.4 \pm 4.6$ \\
\hline WHR (m) & $0.95 \pm 0.006$ & $0.91 \pm 0.006$ & $0.95 \pm 0.003$ & $0.94 \pm 0.004$ & $0.96 \pm 0.002$ & $0.95 \pm 0.002$ \\
\hline $\mathrm{VO}_{2} \max (\mathrm{ml} / \mathrm{kg}$ per $\min )$ & $26.3 \pm 4.8$ & $33.2 \pm 4.9^{\mathrm{a}}$ & $24.6 \pm 8.8$ & $29.1 \pm 7.8^{\mathrm{a}}$ & $23.0 \pm 6.4$ & $20.5 \pm 5.0$ \\
\hline
\end{tabular}

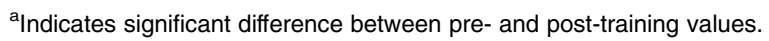




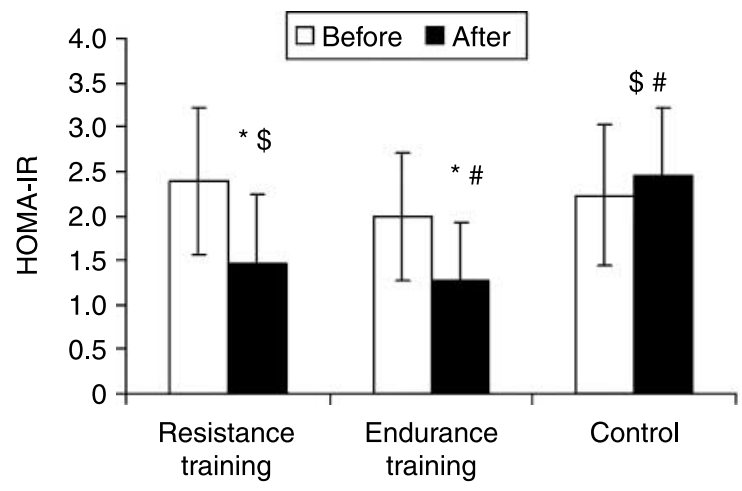

Figure 1 Changes (mean \pm s.D.) in HOMA-IR before and after endurance training, resistance training and control condition. *Significant $(P<0.05)$ difference between pre- and post-training values for each training group, ${ }^{\$}$ significant difference $(P<0.05)$ between endurance training and control trials and " difference $(P<0.05)$ between resistance training and control trials.

\section{Discussion}

Short-duration (8-20 weeks) circuit weight training increased $\mathrm{VO}_{2}$ max by $\sim 4$ and $8 \%$ in men and women respectively (22). We found a 5\% improvement in $\mathrm{VO}_{2}$ max , which supports the finding of Gettman \& Pollock (22) and indicates that the intensity and duration of training were sufficient to induce the required physiological improvements.

In the present study, 12 weeks of endurance and resistance training increased insulin sensitivity by 35 and $38 \%$ respectively. These findings confirm those of previous studies that found improvement in insulin sensitivity after endurance training in obese and healthy individuals $(3,8,12,15)$. Several mechanisms have been proposed to be responsible for the increases in insulin sensitivity after exercise training (28-32). These include increased post-receptor insulin signalling (30), increased glucose transporter protein and mRNA (31), increased activity of glycogen syntheses and hexokinase (29), decreased release and increased clearance of free fatty acids (28), increased muscle glucose delivery and

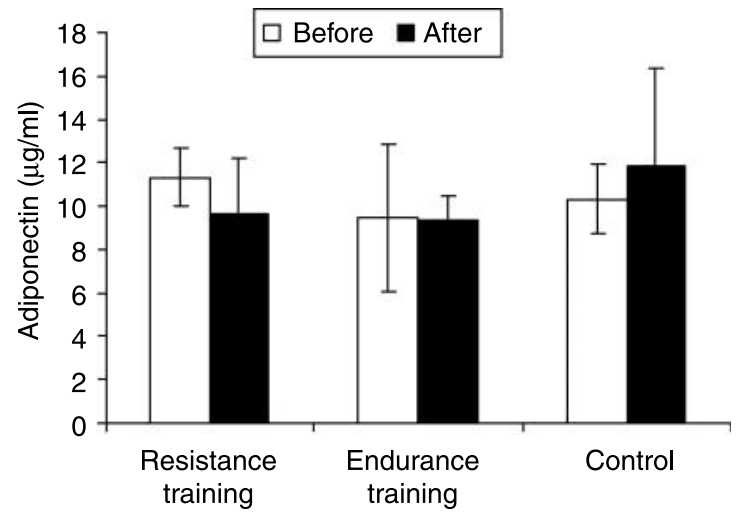

Figure 2 Adiponectin concentrations (mean \pm s.D.) before and after 12 weeks of endurance training, resistance training and control condition. changes in muscle composition (32). The mechanisms responsible for the effect of resistance training on glucose homeostasis and insulin sensitivity are similar to endurance training (33). Although the mechanism responsible for the improvements in insulin sensitivity after resistance training cannot be deduced from the present study, it has been shown (34) that low-intensity strength training leads to increases in the protein content of GLUT4, insulin receptors, glycogen synthase and protein kinase $\mathrm{B}$, without an increase in muscle mass. An interesting finding from the present study is that insulin sensitivity was improved without changes in body weight, WHR and BMI. This finding supports those of previous studies $(35,36)$ and suggests that both endurance and circuit weight training improve insulin sensitivity independent of changes in body composition. Restoring insulin sensitivity by aerobic exercise and circuit weight training might be mediated mainly by mechanisms other than adiponectin, for instance, by the AMP-activated protein kinase pathway (10).

Twelve weeks of endurance and circuit weight training did not change serum adiponectin concentrations, in accordance with the general consensus (3, 8-11). There are only few endurance-training studies that have reported different findings (12-15). Yatagai et al. (15) reported decreases in adiponectin concentration $16 \mathrm{~h}$ after training. This reduction in adiponectin could be due to the direct effect of the last training session rather than a more general effect of a training programme because the blood sample was taken $16 \mathrm{~h}$ after the last bout. However, Kriketos et al. (12) and Oberbach et al. (13) have reported increases in adiponectin concentration after short-term physical training in overweight subjects and patients with impaired glucose tolerance and type 2 diabetes. Similarly, Ring-Dimitriou et al. (14) investigated the changes in plasma adiponectin over 24 months of exercise intervention in middle-aged adults with predisposition to metabolic syndrome and found increases in plasma adiponectin concentration with $15 \%$ improvement in cardiorespiratory fitness. These discrepant results may be attributed to differences in timing in blood sampling, variation in the exercise protocols and differences in subject populations.

Few resistance-training studies that have investigated changes in adiponectin have also reported conflicting results (19-21). Klimcakova et al. (20) reported no changes in adiponectin concentration in response to 3 months of resistance training performed thrice a week at $60-70 \%$ of $1-\mathrm{RM}$ with $12-15$ repetitions for each exercise (30-45 min per session). In an interesting study, Fatouros et al. (19) investigated the effects of 6 months of resistance training at different intensities (low, moderate and high intensities) on adiponectin concentration in elderly individuals. They reported significant increases in adiponectin after moderateand high-intensity training but not after low-intensity training, which were accompanied by weight 
reductions. Recently, Brooks et al. (21) demonstrated significant increases in adiponectin concentration after 14 weeks of high-intensity resistance training. In the present study, adiponectin concentration did not change following 12 weeks of circuit weight training at $50-60 \% 1-\mathrm{RM}$, which is a low-intensity protocol. Our findings support those of Klimcakova et al. (20) and the low-intensity protocol of Fatouros et al. (19). Therefore, it can be concluded that changes in adiponectin in response to resistance training might be intensity related. However, further studies are required to confirm this in different populations and investigate the mechanism(s) responsible for these changes.

In the present study, both endurance and resistance training caused a significant decrease in body fat percentage but had no significant effect on body weight and BMI (Table 1). The lack of effect of training on adiponectin in the present study might be due to the absence of reductions in body weight and BMI. Increases in adiponectin concentration by dietary restriction or gastric bypass surgery have been accompanied by massive weight reductions $(2,7,8)$. Therefore, it seems likely that the weight reduction has a considerable effect on the increases in adiponectinaemia (15); without such a weight loss, exercise training cannot increase plasma adiponectin levels. It is possible that tumour necrosis factor- $\alpha$ (TNF- $\alpha$ ) and IL- 6 reductions after training or weight loss might be responsible for the regulation of adiponectin, since the local production of IL- 6 and TNF- $\alpha$ in the adipose tissue may directly inhibit the local production of adiponectin (37). Although our findings are supported by the above mechanisms and findings, because of the low number of subjects recruited in the present study the possibility of committing a statistical measurement error type $\Pi$ is high.

It is also noted that exercise and weight loss improve insulin sensitivity either partially or completely via different mechanisms, with adiponectin functioning as a contributory factor to enhanced insulin action associated with weight loss but not to exercise-related improvements in insulin action. This notion is supported by previous randomised controlled trials comparing the effects of weight loss and aerobic exercise on glucose tolerance (8).

Although adiponectin concentrations were unchanged following endurance and circuit weight training, serum adiponectin levels at baseline were significantly and negatively correlated with body fat percentage $(R=-0.64)$, WHR $(R=-0.59)$ and BMI $(R=-0.74)$. These results are in agreement with previous studies $(11,19,38)$. Based on the negative correlation between adiponectin and body fat percentage found in the present study and to reduce the risks of atherosclerosis by reducing body fat, it could be suggested that patients and normal sedentary individuals need to participate in endurance- and resistance-training programmes that lead to loss of body weight and fat reduction.

It is also important to note that, in the present study and in the other studies that have investigated the effects of training on adiponectin levels, the total adiponectin level has been measured, whereas different forms of adiponectin and its receptors have recently been identified (39). It is thought probable that the biological action of adiponectin is related more to levels of these structural variants than to total adiponectin levels (3). This use of total adiponectin levels could be one source of the discrepancies in the results from previous studies, in addition to differences in training protocols, subjects' status and laboratory methodology.

The selection of time period (4 days after training) to measure insulin sensitivity and adiponectin in the present study was based upon previous studies that had shown a sustained effect on these variables 4-7 days after training $(40,41)$. However, further studies are required to estimate the effects of the last exercise bout and the process of 'detraining' on these variables. In addition, more studies are needed to establish the effects of exercise intensity and duration (particularly with resistance training) on insulin sensitivity and inflammatory markers.

Both endurance and circuit weight training resulted in similar changes in physiological and glucose metabolic profiles, including insulin sensitivity and serum adiponectin. These findings might be because of the form of resistance training that was used in the present study. Circuit weight training is often used to improve body composition, muscle strength, endurance and cardiovascular fitness, and it improves cardiovascular fitness (similar to endurance training) more than any other form of resistance training (22).

In summary, despite improvement in insulin sensitivity, 12 weeks of endurance and circuit weight training had no effect on adiponectin concentrations in healthy middle-aged men. In addition, serum adiponectin levels were found to be significantly and negatively correlated with body fat percentage, WHR and BMI. Therefore, it is concluded that increases in insulin sensitivity induced by endurance and circuit weight training are not related to changes in adiponectinaemia in healthy middle-aged men, and that the two forms of training had similar effects on all parameters measured in the present study.

\section{Acknowledgements}

This project was funded by Tarbiat Moallem University of Sabzevar in Iran. The authors wish to thank the volunteers for their enthusiastic participation in this study and also would like to thank Prof. Jim Waterhouse for reading the manuscript. 


\section{References}

1 Scherer PE, Williams S, Fogliano M, Baldini G \& Lodish HF. A novel serum protein similar to $\mathrm{C}_{14}$, produced exclusively in adipocytes. Journal of Biological Chemistry $199527026746-26749$.

2 Hotta K, Funahashi T, Arita Y, Takahashi M, Matsuda M, Okamato Y, Iwahashi H, Kuriyama H, Ouchi N, Maeda K, Nishid M, Kihara S, Sakai N, Nakajima T, Hasegawa K, Muraguchi M, Ohmoto Y, Nakamura T, Yamashita S, Hanafusa T \& Matsuzawa Y. Plasma concentration of a novel, adipose specific protein, adiponectin, in type 2 diabetic patients. Arteriosclerosis, Thrombosis, and Vascular Biology 200020 1595-1599.

3 Marcell TJ, MCAuley KA, Traustadottir T \& Reaven PD. Exercise training is not associated with improved levels of C-reactive protein or adiponectin. Metabolism: Clinical and Experimental $2005 \mathbf{5 4}$ 533-541.

4 Ahima RS. Metabolic actions of adipocyte hormones: focus on adiponectin. Obesity 2006 Suppl $19 S-15$ S.

5 Laukkanen JA, Kurl S \& Salonen JT. Cardiorespiratory fitness and physical activity as risk predictors of future atherosclerotic cardiovascular diseases. Current Atherosclerosis Reports 20024 468-476.

6 Thompson PD, Buchner D, Pina IL, Balady GJ, Williams MA, Marcus BH, Berra K, Blair SN, Costa F, Franklin B, Fletcher GF, Gordon NF, Pate RR, Rodriguez BL, Yancey AK \& Wenger NK. Exercise and physical activity in the prevention and treatment of atherosclerotic cardiovascular disease: a statement from the Council on Clinical Cardiology (Subcommittee on Exercise, Rehabilitation, and Prevention) and the Council on Nutrition, Physical Activity, and Metabolism (Subcommittee on Physical Activity). Circulation 2003107 3109-3116.

7 Yang WS, Lee WJ, Funahashi T, Tanaka S, Matsuzawa Y, Chao CL, Chen CL, Tai TY \& Chuang LM. Weight reduction increases plasma levels of an adipose-derived anti-inflammatory protein, adiponectin. Journal of Clinical Endocrinology and Metabolism $2001 \mathbf{8 6}$ 3815-3819.

8 Hulver MW, Zheng D, Tanner CJ, Houmard JA, Kraus WE, Slentz CA, Sinha MK, Pories WJ, MacDonald KG \& Dohm GL. Adiponectin is not altered with exercise training despite enhanced insulin action. American Journal of Physiology. Endocrinology and Metabolism 2002283 E861-E865.

9 Boudou P, Sobngwi E, Mauvais-Javis F, Vexiau P \& Gautier JF. Absence of exercise-induced variations in adiponectin levels despite decreased abdominal adiposity and improved insulin sensitivity in type 2 diabetic men. European Journal of Endocrinology 2003149 421-424.

10 Yokoyama H, Emoto M, Araki T, Fujiwara S, Motoyama K, Morioka T, Koyama H, Shoji T, Okuno Y \& Nishizawa Y. Effect of aerobic exercise on plasma adiponectin levels and insulin resistance in type 2 diabetes. Diabetes Care 200427 1756-1758.

11 Hara T, Fujiwara H, Nakao H, Mimura T, Yoshikawa T \& Fujmoto S. Body composition is related to increase in plasma adiponectin levels rather than training in young obese men. European Journal of Applied Physiology 2005 74 520-526.

12 Kriketos AD, Gan SK, Poynten AM, Furler SM, Chisholm DJ \& Campbell LV. Exercise increases adiponectin levels and insulin sensitivity in humans. Diabetes Care 200427 629-630.

13 Oberbach A, Tonjes A, Kloting N, Fasshauer M, Kratzsch J, Busse MW, Paschke R, Stumvoll M \& Bluher M. Effect of a 4 week physical training program on plasma concentrations of inflammatory markers in patients with abnormal glucose tolerance. European Journal of Endocrinology 2006154 577-585.

14 Ring-Dimitriou S, Paulweber B, von Duvillard SP, Stadlmann M, LeMura LM, Lang J \& Muller E. The effect of physical activity and physical fitness on plasma adiponectin in adults with predisposition to metabolic syndrome. European Journal of Applied Physiology $200698472-481$.

15 Yatagai T, Nishida Y, Nagasaka S, Nakamura T, Tokuyama K, Shindo M, Tanaka H \& Ishibashi S. Relationship between exercise training-induced increase in insulin sensitivity and adiponectinemia in healthy men. Endocrinology Journal 200350 233-238.
16 Feigenbaum MS \& Pollock ML. Prescription of resistance training for health and disease. Medicine and Science in Sports and Exercise $19993138-45$.

17 Kraemer WJ, Ratamess NA \& French DN. Resistance training for health and performance. Current Sports Medicine Reports 20021 $165-171$.

18 Kraemer WJ. General adaptations to resistance and endurance training programs. In Essentials of Strength Training and Conditioning, pp 127-150. Ed. TR Baechle, Champaign, IL: Human Kinetics, 1994.

19 Fatouros IG, Tournis S, Leontsini D, Jamurtas AZ, Sxina M, Thomakos P, Manousaki M, Douroudos I, Taxildaris K \& Mitrakou A. Leptin and adiponectin responses in overweight inactive elderly following resistance training and detraining are intensity related. Journal of Clinical Endocrinology and Metabolism $2005905970-5977$.

20 Klimcakova E, Polak J, Moro C, Hejnova J, Majercik M, Viguerie N, Berlan M, Langin D \& Stich V. Dynamic strength training improves insulin sensitivity without altering plasma levels and gene expression of adipokines in subcutaneous adipose tissue in obese men. Journal of Clinical Endocrinology and Metabolism 200691 $5107-5112$

21 Brooks N, Layne JE, Gordon PL, Roubenoff R, Nelson ME \& Castaneda-Sceppa C. Strength training improves muscle quality and insulin sensitivity in Hispanic older adults with type 2 diabetes. International Journal of Medical Sciences 20064 19-27.

22 Gettman LR \& Pollock ML. Circuit weight training: a critical review of its physiological benefits. Physician and Sportsmedicine $1981944-60$.

23 Kraemer WJ, Hakkinen K, Newton RU, Nindl BC, Volek JS, McCormick M, Gotshalk LA, Gordon SE, Fleck SJ, Campbell WW, Putukian M \& Evans WJ. Effects of heavy-resistance training on hormonal response patterns in younger versus older men. Journal of Applied Physiology 199987 982-992.

24 Ahmadizad S \& El-Sayed MS. The effects of graded resistance exercise on platelet aggregation and activation. Medicine and Science in Sports and Exercise 200335 1026-1033.

25 Matthews DR, Hosker JP, Rudenski AS, Naylor BA, Treacher DF \& Turner RC. Homeostasis model assessment: insulin resistance and beta-cell function from fasting plasma glucose and insulin concentrations in man. Diabetologia 198528 412-419.

26 Emoto M, Nishizawa Y, Maekawa K, Hiura Y, Kanda H, Kawagishi T, Shoji T, Okuno Y \& Morii H. Homeostasis model assessment as a clinical index of insulin resistance in type 2 diabetic patients treated with sulfonylureas. Diabetes Care 199922 818-822.

27 Katsuki A. Sumida Y, Gabazza EC, Murashima S, Furuta M, ArakiSasaki R, Hori Y, Yano Y \& Adachi Y. Homeostasis model assessment is a reliable indicator of insulin resistance during follow-up of patients with type 2 diabetes. Diabetes Care $2001 \mathbf{2 4}$ $362-365$.

28 Ivy JI, Zderic TW \& Fogt DL. Prevention and treatment of noninsulin dependent diabetes mellitus. Exercise and Sport Sciences Reviews 199227 1-35.

29 Ebeling P, Bourey R, Koranyi L, Tuominen JA, Groop LC, Henriksson J. Mueckler M, Sovijarvi A \& Koivisto VA. Mechanism of enhanced insulin sensitivity in athletes: increased blood flow, muscle glucose transport protein (Glut4) concentration, and glycogen synthase activity. Journal of Clinical Investigation 199392 $1623-1631$

30 Dela F, Handberg A, Mikines KJ, Vinten J \& Galbo H. GLUT4 and insulin receptor binding and kinase activity in trained human muscle. Journal of Physiology 1993469 615-624.

31 Dela F, Ploug T, Handberg A, Petersen LN, Larsen JJ, Mikines KJ \& Galbo H. Physical training increases muscle GLUT4 protein and mRNA in patients with NIDDM. Diabetes 199443 862-865.

32 Andersson A, Sjodin A, Olsson R \& Vessby B. Effects of physical exercise on phospholipid fatty acid composition in skeletal muscle. American Journal of Physiology $1998 \mathbf{2 7 4}$ E432-E438.

33 Castaneda C, Layne JE, Munoz-orians L, Gordon PL, Walsmith J, Foldvari M, Roubenoff R, Tucker KL \& Nelson ME. A randomized 
controlled trial of resistance exercise training to improve glycemic control in older adults with type 2 diabetes. Diabetes Care 200225 2335-2341.

34 Barnett JB, Woods MN, Lamon-Fava S, Schaefer EJ, McNamara JR, Spiegelman D, Hertzmark E, Goldin B, Longcope C \& Gorbach SL. Plasma lipid and lipoprotein levels during the follicular and luteal phases of the menstrual cycle. Journal of Clinical Endocrinology and Metabolism $200489776-782$.

35 Poehlman ET, Dvorak RV, Denio WF, Brochu M \& Ades PA. Effects of resistance training and endurance training on insulin sensitivity in non obese, young women. A controlled randomized trail. Journal of Clinical Endocrinology and Metabolism $2000 \mathbf{8 5}$ 2463-2468.

36 Duncan GE, Perri MG, Theriaque DW, Hutson AD, Eckel RH \& Stacpoole PW. Exercise training, without weight loss, increases insulin sensitivity and postheparin plasma lipase activity in previously sedentary adults. Diabetes Care 200326 557-562.

37 Bruun JM, Lihn AS, Verdich C, pedersen SB, Toubro S, Astrup A \& Richelsen B. Regulation of adiponectin by adipose tissue-derived cytokines: in vivo and in vitro investigations in humans. American Journal of Physiology. Endocrinology and Metabolism $2003 \mathbf{2 8 5}$ E527-E533.
38 Matsubara M, Maruoka S \& Katayose S. Inverse relationship between plasma adiponectin and leptin concentrations in normalweight and obese women. European Journal of Endocrinology 2002 147 173-180.

39 Yamauchi T, Kamon J, Ito Y, Tsuchida A, Yokomizo T, Kita S, Sugiyama T, Miyagishi M, Hara K, Tsunoda M, Murakami K, Ohteki T, Uchida S, Takekawa S, Waki H, Tsuno NH, Shibata Y, Terauchi Y, Froguel P, Tobe K, Koyasu S, Taira K, Kitamura T, Shimizu T, Nagai R \& Kadowaki T. Cloning of adiponectin receptors that mediate antidiabetic metabolic effects. Nature $2003423762-769$.

40 Tonino RP. Effect of physical training on the insulin resistance of aging. American Journal of Physiology 1989256 E352-E356.

41 Hughes VA, Fiatarone MA, Fielding RA, Kahn BB, Ferrara CM, Shepherd P, Fisher EC, Wolfe RR, Elahi D \& Evans WJ. Exercise increases muscle GLUT-4 levels and insulin action in subjects with impaired glucose tolerance. American Journal of Physiology 1993 264 E855-E862.

Received 3 April 2007

Accepted 23 August 2007 